\title{
Hepato-Renal Toxicity of Titanium Dioxide Nanoparticles and The Protective Effects of Moringa Oleifera Leaves Extract and Vitamin E in Male Albino Rats Doaa S. A. El-behairy ${ }^{1}$, Nayera H. Diaa Eldin ${ }^{1}$, Entsar E. Elbadry ${ }^{1}$, Amira A. Mohamed ${ }^{2}$ and Islam M. Farrag ${ }^{1}$ \\ ${ }^{1}$ Forensic Medicine and Clinical Toxicology, Faculty of Medicine for Girls, Al-Azhar University, Egypt, ${ }^{2}$ Genetic and Cell Biology, National Research Centre, Dokki, Egypt \\ Corresponding Author: Doaa S. A. El-behairy, Tel.:01028330856, E-mail: doaasabryelbehairy@ gmail.com
}

\begin{abstract}
Background: Titanium dioxide nanoparticles (TDN) one of the most common nanomaterial used in a wide range of applications. Moringa oleifera leaves extract (MOLE) has hepato- and nephron-protective effects amongst other medicinal and nutritional benefits. Vitamin E (Vit. E) is an important lipid soluble vitamin.

Aim: The present work aimed to study hepato-renal toxicity of TDN in adult male albino rats through biochemical and histopathological study and protective effects of either MOLE or Vit. E or both.

Materials and Methods: 49 adult male albino rats were divided randomly into 7 groups ( 7 rats each). Group 1: served as control, Group 2: Rats received (MOLE) once daily by oral gavage Group 3: Rats received (Vit. E) once daily by oral gavage Group 4: Rats received TDN subcutaneous on alternate days Group 5: Rats coadministrated TDN and MOLE Group 6: Rats co-administrated TDN and (Vit. E), Group 7: Rats coadministrated TDN, (MOLE) and vitamin E. All groups received the treatment for four weeks, then blood samples were collected for assessment of liver function markers and kidney function markers. Also, Liver and kidney were excised for histopathological examination.

Results and Conclusion: TDN treated animals recorded a significant increase in ALT, AST. ALP, total bilirubin, urea and creatinine and a significant decrease in total protein. Significant improvement occurred on co-administration of either (MOLE) or (Vit.E) or both. Histopathological lesion in both liver and kidney which were observed in TDN treated animals improved on co-administration of either (MOLE) or (Vit. E) or both.
\end{abstract}

Keywords: TDN, Moringa oleifera leaves extract, vitamin E, hepatotoxicity and nephrotoxicity.

\section{INTRODUCTION}

Nanoparticles can be defined as objects ranging in size from one to one hundred nanometers and used for many purposes such as in medicine, various branches of industry production such as solar and oxide fuel batteries for energy storage, to wide incorporation into diverse materials of everyday use such as cosmetics ${ }^{(1)}$.

Titanium dioxide nanoparticles (TDN) one of the most widely manufactured nanoparticles on a global scale, depending on its excellent physicochemical properties. They are one of nanoparticles used in industry as well as in consumer products, account for over $70 \%$ of the total production volume of nanoparticles worldwide. They are white pigment and used for its brightness and very high refractive index. It has unique characters such as small size, large surface area and high reactivity that allow themto enter quickly to the human body and produce potential health risk on human ${ }^{(2)}$. TDN have two major forms of crystal structures, named rutile and anatase. Both are toxic but the anatase form may produce much more toxic than rutile nanoparticles because of the photo catalytic properties of anatase and these particles are usually associated with oxidizing mechanisms of an organism, which is capable to generating reactive oxygen species (ROS) including oxidative stress and DNA damage ${ }^{(3)}$.
Medicinal plants are known to exhibit their antioxidative effects by scavenging the reactive oxygen species (ROS) and modulating the antioxidant defence mechanisms, which are capable to generating reactive oxygen species (ROS) including oxidative stress and DNA damage ${ }^{(3)}$. Medicinal plants are known to exhibit their antioxidative effects by scavenging the reactive oxygen species (ROS) and modulating the antioxidant defence mechanisms. The world market for alternative medicine is being increased. The global market for plant derived medicine alone has reached $\$ 5$ trillion and is increasing at a rate of about $11 \%$ per annum. This rapid growth in the market of the herbal/alternative medicines indicates its acceptance and popularity worldwide ${ }^{(4)}$.

Moringa oleifera is plant, known in the tropical and subtropical countries ${ }^{(5)}$. A variety of benefits have been attributed to the leaf extract of Moringa including anticancer, anti-inflammatory, bactericidal, antiatherosclerotic, antioxidant, neuro and hepatoprotective ${ }^{(6)}$.

Vitamins are good antioxidants protect the tissue from oxidative stress. vitamin $\mathrm{E}$ consists of eight natural fat soluble compounds, including 4 tocopherols [alpha, beta, gamma and delta tocopherol] and 4 tocotrienols [alpha, beta, gamma and delta tocotrienol] ${ }^{(7)}$. 
Vitamin E is a lipid soluble vitamin, acts as a free radical scavenging and stabilizing cell membranes, thus maintaining cell permeability ${ }^{(8)}$.

There are multiple reports Farag et al., (26) and Abd et al ., ${ }^{(32)}$ available on the protective effects of Moringa oleifera leaves extract or vitamin $E$ individually against various xenobiotic induced toxicity in experimental animals. Still to date the reports are scanty regarding the combined alleviated efficacy of Moringa oleifera leaves extract in combination with vitamin $\mathrm{E}$ on TDN induced toxicity in rats. In view of the above considerations, the present work aimed to study hepato-renal toxicity of titanium dioxide nanoparticles in adult male albino rats through biochemical and histopathological study and protective effects of either Moringa oleifera leaves extract or vitamin $\mathrm{E}$ or both.

\section{MATERIALS AND METHODS}

(A) Materials

I- Experimental Animals:

49 male Albino rats of uniform strain with body weight about 100 grams, obtained from the animal's farm of Helwan, Egypt.

\section{II-Substances used:}

1-Titanium dioxide nanoparticles (TDN), white powder anatase form $(5-30 \mathrm{~nm})$ was purchased from petroleum researches institute, Nasr city, Cairo, Egypt.

2- Moringa olifera leaves extract (MOLE) was purchased from National Research Center, Dokki, Giza, Egypt.

3-Vitamin E ( $\alpha$ tochopherol acetate) $(1 \mathrm{gm} / \mathrm{ml})$ oily was purchased from Al-Khahera company for pharmaceuticals, Cairo, Egypt.

4-Commercial rat's diet obtained from local market.

\section{III-Biochemical kits:}

The following parameters were done at cell Biology Department of National Research Center in Dokki Giza, Egypt: Liver function markers and Kidney function markers.

All markers were assayed by using commercial Kits, which were purchased from Bio diagnostic company.

(B) Methods

Preparation of materials:

I- Experimental animals:

- Handling:

The handling of animals followed the rules for the experimental research ethics approved by Research Ethics Committee at Faculty of Medicine for Girls Al-Azhar University, Cairo, Egypt according to Kostomitsopoulos and Đurašević( ${ }^{(9)}$, the animals were kept in the Animal House at Faculty of
Medicine for Girls, Al-Azhar University. They were housed in clean plastic cages with metal covers; their floors were covered by wood flakes, at room temperature and 12 hours light/dark cycle. The animals were subjected to 7 days period of passive preliminaries in order to adapt themselves to their new environment and to ascertain their physical wellbeing ${ }^{\mathbf{( 1 0 )}}$.

\section{- Experimental Design:}

After one week of acclimatization, animals were divided into seven groups each group contained seven rats, as follow:

Group 1: served as control, rats received $0.15 \mathrm{ml}$ distilled water subcutaneous once daily for four weeks. Group 2: Rats received MOLE (2.6 gm/ $\mathrm{kg}$ ) body weight once daily for four weeks by oral gavage according to Eshak et al. ${ }^{(11)}$. Group 3: Rats received Vit. E ( $100 \mathrm{mg} / \mathrm{kg}$ ) body weight once daily by oral gavage for four weeks according to Azim et al . ${ }^{(2)}$. Group 4 Rats received TDN (150 $\mathrm{mg} / \mathrm{kg}$ ) body weight subcutaneous after suspending it in distilled water for four weeks on alternate days according to Shakeel et al. ${ }^{(13)}$. Group 5: Rats coadministrated TDN and MOLE for four weeks. Group 6: Rats co-administrated TDN and Vit. E for four weeks. Group 7: Rats co-administrated TDN, MOLE and Vit. E for four weeks.

Sampling:

At the end of experimental period (4 weeks), this duration was considered as subacute toxicity according to Shi et al ., ${ }^{(14)}$ and after 24 hours from the last dose rats were sacrificed after being anaesthetized with diethyl ether by inhalation.

1-Blood samples: Blood samples were collected from the retro-orbital venous plexus before they were sacrificed in sterile separator tubes. The blood samples were centrifuged at $2000 \mathrm{rpm}$ for $15 \mathrm{~min}$., to separate the sera for assessment of liver function markers (ALT, AST, Alkaline phosphatase, total bilirubin and total protein) and kidney function markers (urea and creatinine) .

2- Tissue samples: Liver and kidney were excised for histopathological examination.

II-Substances used:

- Preparation of titanium dioxide nanoparticles suspension:

According to Helmy et al. ${ }^{(15)}$.

- Preparation of Moringa oleifera leaves extract : According to Rahman et al. ${ }^{(16)}$.

- Preparation of Vit. E: it is used in its oily form Biochemical studies:

1) Liver function markers (ALT, AST, alkaline phosphatase, total bilirubin and total protein): 
- Quantitative estimation of serum alanine transaminases (ALT) activity: According to IFCC (17).

- Quantitative estimation of serum aspartate transaminase (AST) activity: According to the International Federation of Clinical Chemistry (IFCC) ${ }^{(17)}$.

- Quantitative estimation of serum alkaline phosphatase (ALP): According to Scandinavian society ${ }^{(18)}$.

- Quantitative estimation of total Bilirubin: According to Walter and Gerade $\left({ }^{19}\right)$.

- Quantitative estimation of total protein: according to Gomal et al. ${ }^{(20)}$.

2) Kidney function markers (urea and creatinine):

- Quantitative estimation of serum urea concentration: According to Fawcett and Soctt (21).

- Quantitative estimation of serum creatinine concentration: According to Bartles and Bohmen (22).

\section{Histopathological studies:}

Liver and kidney sections were stained with hematoxylin and eosin stain: as a routine method for studying the general histological structure of liver and kidney then examined under light microscope ${ }^{(23)}$.

\section{Statistical analysis}

Values were presented as mean and standard deviation (SD) values. Data were explored for normality using Kolmogorov-Smirnov test of normality. The results of Kolmogorov-Smirnov test indicated that most of data were normally distributed (parametric data), so one way analysis of variance ANOVA test was used to compare between groups, followed by Tukey's post hoc test for pairwise comparisons. The significance level was set at $\mathrm{p} \leq 0.05$. Statistical analysis was performed with SPSS 16.0 (Statistical Package for Scientific Studies, SPSS, Inc., Chicago, IL, USA) for Windows.

\section{RESULTS}

\section{I- Biochemical results}

1) Liver function markers:

The data in Table (1) recorded that, subcutaneous administration of TDN to the male albino rats caused an adverse effect on the liver function represented by significant elevation in serum ALT, AST, ALP and total bilirubin levels and significant decrease in serum total protein level in comparison to control group. However, coadministration of either MOLE or Vit. E or both revealed a significant improvement in these parameters in comparison to TDN group.

\section{2) Kidney function markers:}

The data in Table (2) recorded that, subcutaneous administration of TDN to the male albino rats caused an adverse effect on the kidney function represented by significant elevation in serum urea and creatinine in comparison to control group. However, co-administration of either MOLE or Vit. E or both revealed a significant improvement in these parameters in comparison to TDN group.

Table (1) shows the toxic effect of TDN and protective effect of MOLE or vitamin E or both on different studied groups as regard liver function markers.

\begin{tabular}{|l|l|l|l|l|l|}
\hline Groups & ALT & AST & ALP & $\begin{array}{l}\text { Total } \\
\text { Bilirubin }\end{array}$ & Total Protein \\
\hline n=7 rats/group & $\begin{array}{l}\text { Mean } \pm \text { SD } \\
(I U / L)\end{array}$ & $\begin{array}{l}\text { Mean } \pm \quad \text { SD } \\
(\mathrm{IU} / \mathrm{L})\end{array}$ & $\begin{array}{l}\text { Mean } \pm \text { SD } \\
(\mathrm{IU} / \mathrm{L})\end{array}$ & $\begin{array}{l}\text { Mean } \pm \text { SD } \\
(\mathrm{mg} / \mathrm{dl})\end{array}$ & $\begin{array}{l}\text { Mean } \pm \text { SD } \\
(\mathrm{mg} / \mathrm{dl})\end{array}$ \\
\hline 1-Control & $52.99 \pm 0.93^{\mathrm{d}}$ & $50.65 \pm 0.70^{\mathrm{c}}$ & $140.45 \pm 1.06^{\mathrm{c}}$ & $0.31 \pm 0.02^{\mathrm{b}}$ & $13.79 \pm 0.77^{\mathrm{a}}$ \\
\hline 2-MOLE & $52.93 \pm 0.88^{\mathrm{d}}$ & $50.54 \pm 0.55^{\mathrm{c}}$ & $139.93 \pm 0.82^{\mathrm{c}}$ & $0.30 \pm 0.02^{\mathrm{b}}$ & $13.58 \pm 0.69^{\mathrm{a}}$ \\
\hline 3-Vit.E & $53.20 \pm 0.77^{\mathrm{d}}$ & $50.64 \pm 0.81^{\mathrm{c}}$ & $140.06 \pm 0.79^{\mathrm{c}}$ & $0.30 \pm 0.02^{\mathrm{b}}$ & $13.66 \pm 0.68^{\mathrm{a}}$ \\
\hline 4-TDN & $103.63 \pm 2.13^{\mathrm{a}}$ & $79.74 \pm 1.14^{\mathrm{a}}$ & $517.99 \pm 17.42^{\mathrm{a}}$ & $1.79 \pm 0.33^{\mathrm{a}}$ & $7.23 \pm 0.73^{\mathrm{c}}$ \\
\hline 5-TDN+ MOLE & $55.58 \pm 1.23^{\mathrm{b}, \mathrm{c}}$ & $54.96 \pm 0.86^{\mathrm{b}, \mathrm{c}}$ & $151.35 \pm 0.85^{\mathrm{b}}$ & $0.33 \pm 0.02^{\mathrm{b}}$ & $11.85 \pm 0.83^{\mathrm{b}}$ \\
\hline 6-TDN + Vit. E & $56.35 \pm 0.91^{\mathrm{b}}$ & $56.01 \pm 0.69^{\mathrm{b}}$ & $151.44 \pm 0.90^{\mathrm{b}}$ & $0.34 \pm 0.02^{\mathrm{b}}$ & $11.52 \pm 0.65^{\mathrm{b}}$ \\
\hline $\begin{array}{l}\text { 7-TDN+ } \\
\text { MOLE+ Vit. E }\end{array}$ & $54.76 \pm 1.24^{\mathrm{c}}$ & $54.26 \pm 0.87^{\mathrm{b}, \mathrm{c}}$ & $145.26 \pm 1.56^{\mathrm{b}, \mathrm{c}}$ & $0.32 \pm 0.02^{\mathrm{b}}$ & $12.15 \pm 0.74^{\mathrm{b}}$ \\
\hline F Cal. & 1607.883 & 41.769 & 3150.445 & 132.619 & 69.244 \\
\hline F Prob. & 0 & 0 & 0 & 0 & 0 \\
\hline P value & & \multicolumn{5}{|l}{} & \\
\hline
\end{tabular}

TDN=titanium dioxide nanoparticle. MOLE=Moringa oleifera leaves extract. $\mathrm{SD}=$ standard deviation. $\mathrm{n}=$ number. ALT: alanine transaminase. AST: aspartate transaminase. ALP: alkaline phosphatase. Level of significance was set at 0.05

* significant Tukey's post hoc test: means sharing the same superscript letter are not significantly different in the same column. 
Table (2) shows the toxic effect of TDN and protective effect of MOLE or vitamin $E$ or both on different studied groups as regard kidney function markers

\begin{tabular}{|c|c|c|}
\hline Groups & Urea & Creatinine \\
\hline $\mathrm{n}=7$ rats/group & Mean \pm SD (IU/L) & Mean \pm SD $($ IU/L) \\
\hline 1:Control & $23.15 \pm 0.73^{c}$ & $0.59 \pm 0.02^{b}$ \\
\hline 2:MOLE & $22.91 \pm 1.01^{c}$ & $0.58 \pm 0.02^{b}$ \\
\hline 3:Vit.E & $22.97 \pm 0.61^{c}$ & $0.59 \pm 0.02^{b}$ \\
\hline 4:TDN & $71.30 \pm 1.95^{a}$ & $1.56 \pm 0.33^{a}$ \\
\hline 5:TDN+MOLE & $23.92 \pm 0.88^{b, c,}$ & $0.62 \pm 0.02^{b}$ \\
\hline 6:TDN + Vit.E & $24.37 \pm 0.92^{b}$ & $0.63 \pm 0.02^{b}$ \\
\hline 7:TDN+MOLE+Vit.E & $23.86 \pm 0.88^{b, c}$ & $0.60 \pm 0.04^{b}$ \\
\hline F Cal. & 1971.947 & 57.104 \\
\hline F Prob. & $\mathbf{0}$ & $\mathbf{0}$ \\
\hline$P$ value & $<001^{*}$ & \\
\hline
\end{tabular}

TDN=titanium dioxide nanoparticle. MOLE=Moringa oleifera leaves extract $\quad \mathrm{SD}=$ standard deviation. $\mathrm{n}=$ number Level of significance was set at $0.05, *$ significant Tukey's post hoc test: means sharing the same superscript letter are not significantly different in the same column.

\section{III: Histopathological results:}

Liver: Light microscopic examination of liver sections of all rats in control, MOLE and Vit. E groups showed that, the liver tissue has normal histological structure with hepatic cords radiating from the central vein forming anastomosing plates separated by blood sinusoids and the hepatocytes are polyhedral with eosinophilic cytoplasm, central rounded and vesicular nuclei. (Photomicrograph 1). On the other hand, light microscopic examination of liver sections of rats treated with TDN showed that, the hepatocytes appear polyhedral with eosinophilic cytoplasm having central rounded and vesicular nuclei.

There is marked mononuclear cellular infiltration. Also, dilated and congested blood vessel in portal tract area can be seen with thick wall (photomicrograph 2). Furthermore light microscopic examination of liver sections of rats treated with TDN + MOLE showed that the liver tissue has histological structure similar to that in the control group but there is little mononuclear cellular infiltration. Central vein appears dilated and congested (photomicrograph 3). Also, light microscopic examination of liver sections of treated group TDN + Vit. E showed showing that the liver tissue has histological structure similar to that in the control group but there is multiple areas of mononuclear cellular infiltration (photomicrograph 4), but in light microscopic examination of liver sections of rats treated with TDN + MOLE+Vit. E showed that, the liver tissue has histological structure similar to that of the control group but there is little mononuclear cellular infiltration (photomicrograph 5).

Kidney: Light microscopic examination of renal sections of all rats in control, MOLE and vitamin $\mathrm{E}$ groups showed that, the renal tissue has normal histological structure with renal corpuscles surrounded by Bowman's capsules, subcapsular space, proximal convoluted tubule and distal tubule convoluted (photomicrograph 6).

On the other hand, light microscopic examination of kidney sections of rat treated with TDN showed that, dilated and congested blood vessel with thick wall. Multiple large areas of hemorrhage can also be detected. There is mononuclear cellular infiltration (photomicrograph 7). Furthermore light microscopic examination of kidney sections of rat treated with TDN + MOLE showed that, the histological picture is similar to that of the control group. Some mononuclear cellular infiltration can be seen (photomicrograph 8). Also, light microscopic examination of kidney sections of rats treated with TDN + Vit. E showed that, the histological picture is similar to that of the control group. Some mononuclear cellular infiltration and area of hemorrhage can be seen (photomicrograph 9), but in light microscopic examination of kidney sections of rat treated with TDN + MOLE + Vit. E showed that, the renal tissue has histological picture similar to that of the control group. Few mononuclear cellular infiltration and small area of hemorrhage can be seen (photomicrograph 10). 


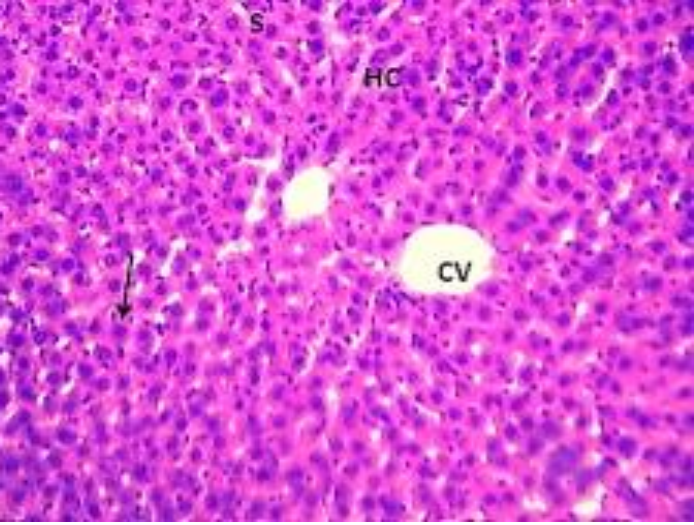

Photomicrograph (1) of a liver section of an adult albino rat in the control, MOLE and Vit. $E$ groups showing that, the liver tissue has normal histological structure with hepatic cords (HC) radiating from the central vein $(\mathrm{CV})$ forming anastomosing plates separated by blood sinusoids (S). Hepatocytes are polyhedral with eosinophilic cytoplasm having central rounded and vesicular nuclei (arrow). (H and E X 200).

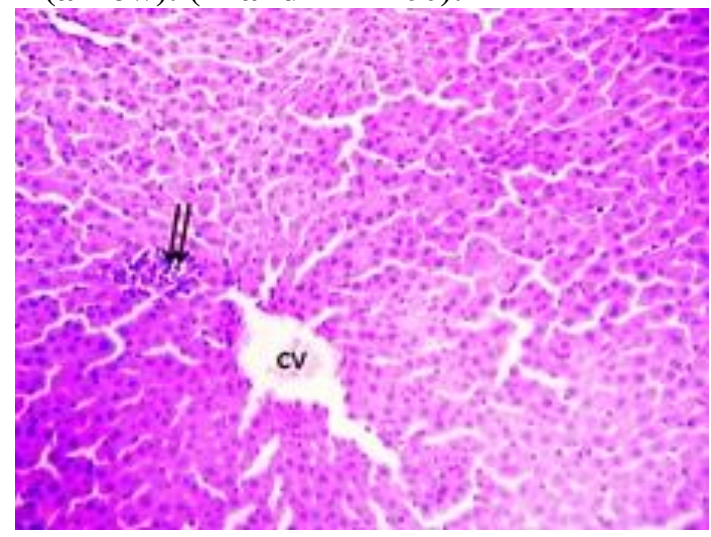

Photomicrograph (3) of a liver section of an adult albino rat treated with TDN + MOLE showing that the liver tissue has histological structure similar to that in the control group but there is little mononuclear cellular infiltration (double arrows). Central vein (CV) appears dilated and congested ( $H$ and $E X ~ 200$ ).

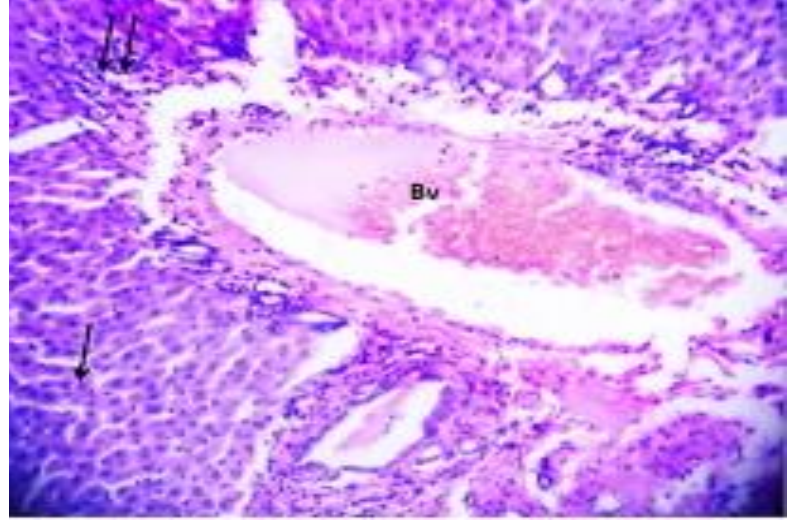

Photomicrograph (2) of a liver section of an adult albino rat treated with TDN showing that, the hepatocytes appear polyhedral with eosinophilic cytoplasm having central rounded and vesicular nuclei (arrow). There is marked mononuclear cellular infiltration (double arrows). Also, dilated and congested blood vessel $(B v)$ in portal tract area can be seen with thick wall (H and E X 200).

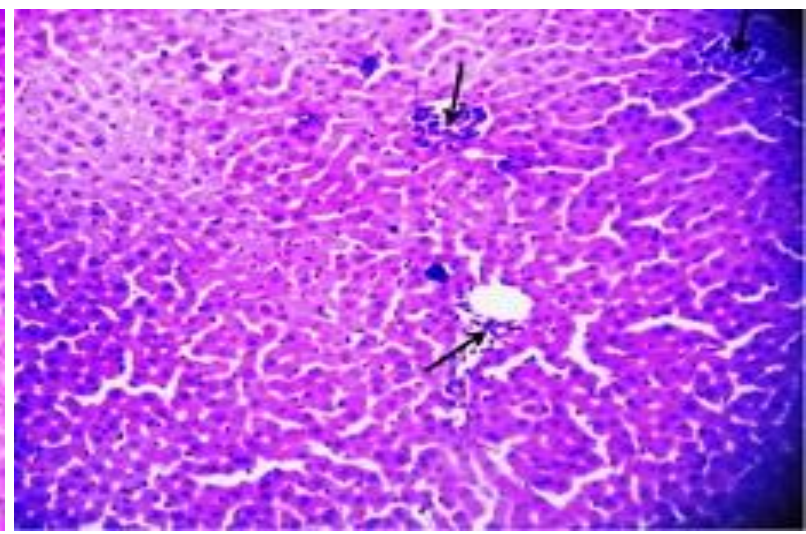

Photomicrograph (4) of a liver section of an adult albino rat treated with TDN +Vit. E showing that, the liver tissue has histological structure similar to that in the control group but there is multiple areas of mononuclear cellular infiltration (arrows). (H and E X 200). 


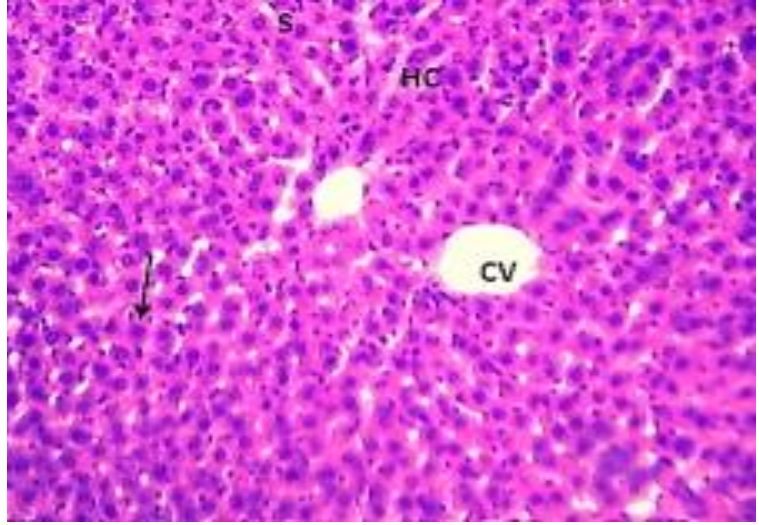

Photomicrograph (5) of a liver section of an adult albino rat treated with TDN + MOLE + Vit. E showing that, the liver tissue has histological structure similar to that of the control group but there is very little mononuclear cellular infiltration (arrow). (H and E X 200).

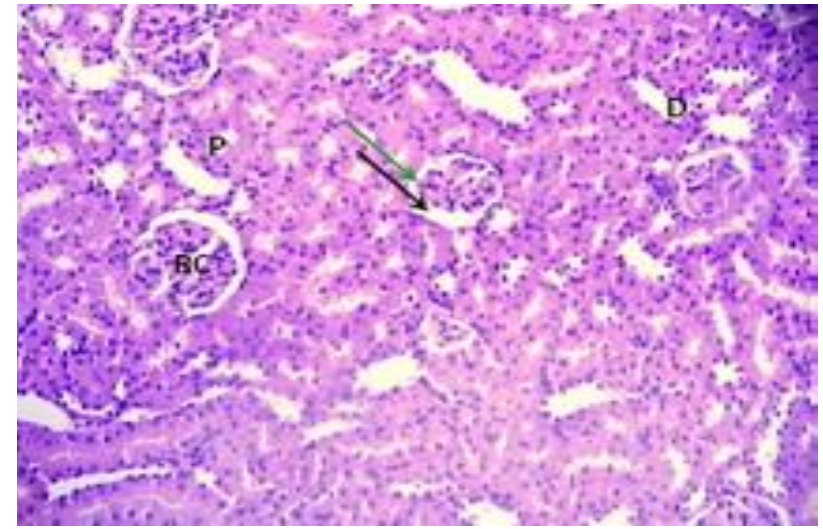

Photomicrograph (6) of a renal section of an adult albino rat in the control, Moringa and Vit. $E$ groups showing that, the renal tissue has normal histological structure with renal corpuscles (RC) surrounded by Bowman's capsules (green arrow), subcapsular space (black arrow), proximal convoluted tubule (P) and distal tubule convoluted (D). (H and E X 200).

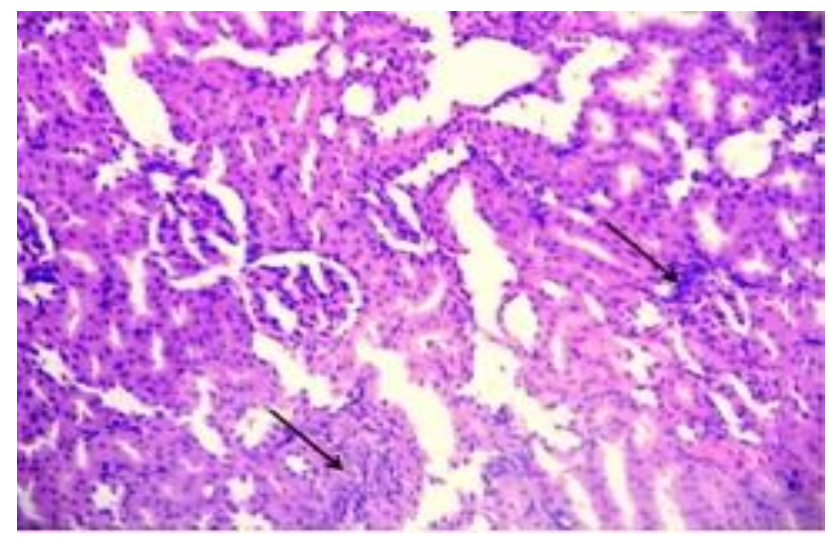

Photomicrograph (8) of a renal section of an adult albino rat treated with TDN + MOLE showing that the histological picture is similar to that of the control group. Some mononuclear cellular infiltration (arrows) can be seen (H and E X 200). 


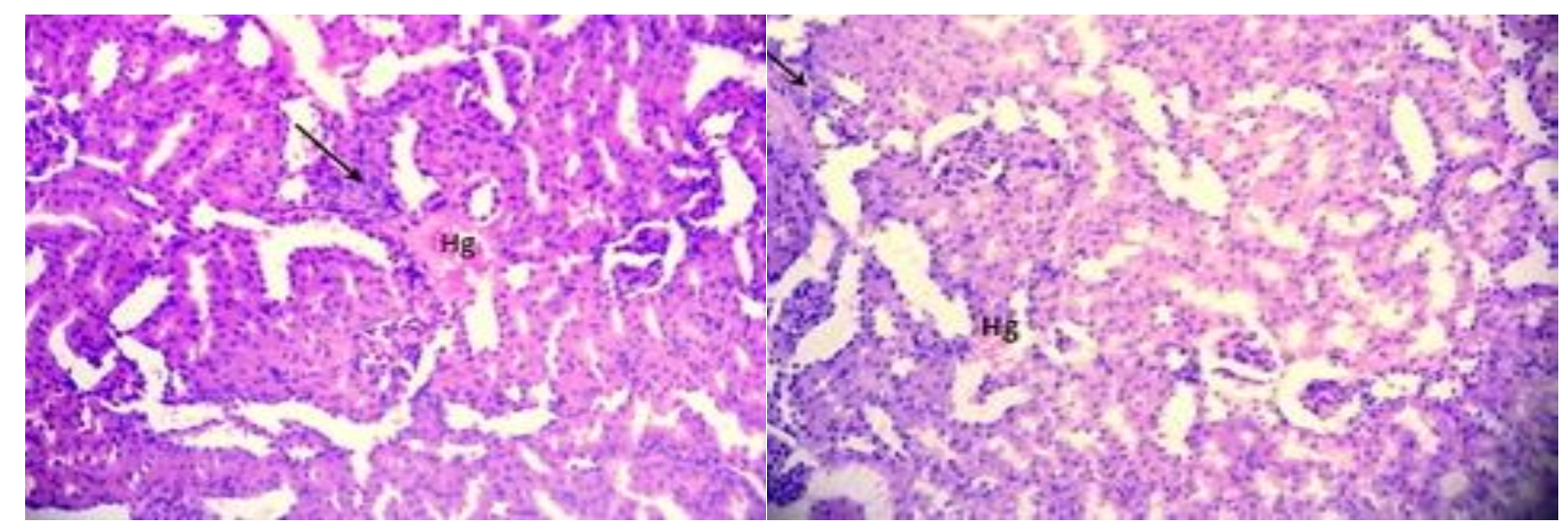

Photomicrograph (9) of a renal section of an adult albino rat treated with TDN + Vit. E showing that the histological picture is similar to that of the control group. Some mononuclear cellular infiltration (arrow) and area of hemorrhage $(\mathrm{Hg})$ can be seen (H and E X 200).

\section{DISCUSSION}

TDN have been widely used in industry and medicine. However, the safety of TDN exposure remains unclear. In the present study, we explored the potential hepato and nephrotoxicity of TDN and the protective effect of either MOLE or Vit. E or both.

The results of the present study as regard liver function markers showed that, subcutaneous administration of TDN on alternate days for 4 weeks to the male albino rats caused an adverse effect on the liver function represented by significant elevation in serum ALT, AST, ALP and total bilirubin levels and significant decrease in serum total protein level .

Our results are supported by Azim et al (12) $^{(12}$ who found that oral administration of TDN to male mice in a dose of $150 \mathrm{mg} / \mathrm{kg}$ bw for 2 weeks produced significant elevation of serum ALT and AST in comparison to control group. Liu et al . ${ }^{(24)}$ stated that, the elevated liver enzymes indicated cellular leakage and loss of functional integrity of cell membranes in the liver due to generation of reactive oxygen species (ROS) which are more destructive and can peroxidize the unsaturated lipids of the cell membrane .

Our results are consistent with Shakeel et al. ${ }^{(13)}$ who found that subcutaneous administration of TDN to rat on alternate days for 28 days in a dose of 50,100 , and $150 \mathrm{mg} / \mathrm{kg}$ bw produced significant elevation of serum ALT, AST and ALP in dose dependent manner due to oxidative stress.
Photomicrograph (10) of a renal section of an adult albino rat treated with TDN + MOLE+ Vit. E showing that the histological picture is similar to that of the control group. Few mononuclear cellular infiltration (arrow) and small area of hemorrhage $(\mathrm{Hg})$ can be seen $(\mathrm{H}$ and $\mathrm{E} X$ 200). our results are supported by Rizk et al. ${ }^{(25)}$ who found that daily administration of intraperitoneally injection of TDN $(50,250$ and 500 $\mathrm{mg} / \mathrm{kg}$ body weight) to mice for 7, 14 and 45 days produced significant elevation in ALT and AST and significant reduction in total protein in comparison to control group in a dose and time dependent due to oxidative stress.

In the present study, co-administration of subcutaneous TDN on alternate days with orally MOLE daily for 4 weeks to male albino rats caused statistically significant decrease in serum ALT, AST, ALP and total bilirubin activities and statistically significant increase in serum total protein in comparison to TDN which indicate improvement.

Also, our results are supported by Farag et al. ${ }^{(26)}$ who found that, rats treated with aflatoxin B1 and received MOLE in a dose of (3.3, 4.0, and 4.7 $\mathrm{g} / \mathrm{kg}$ orally) daily for 1 month have hepatoprotective effect represented by significant reduction in ALT, AST, ALP and total bilirubin and significant increase in total protein in comparison to rats received aflatoxin $\mathrm{B} 1$ alone due to antioxidant effect and stimulation of protein biosynthesis.

The reversal of elevated serum intracellular enzyme levels by Moringa oleifera leaves extract may be attributed to its stabilizing ability of the cell membrane preventing enzyme leakages due to its antioxidant effect and this reversal points us 
Hepato-Renal Toxicity of Titanium Dioxide Nanoparticles...

towards an early improvement in the cellular membrane integrity of the hepatic cell which is a clear manifestation of anti-hepatotoxic effect of Moringa administration ${ }^{(6)}$.

In the present study, co-administration of subcutaneous TDN with orally Vit. E daily for 4 weeks to male albino rats caused statistically significant increase in serum ALT, AST, ALP and total bilirubin activities and statistically significant increase in serum total protein in comparison to TDN which indicate improvement.

Our results are supported by Azim et al. ${ }^{(12)}$ who found that oral administration of TDN to male mice in a dose of $150 \mathrm{mg} / \mathrm{kg}$ bw for 2 weeks followed by oral administration of Vit. E $100 \mathrm{mg} / \mathrm{kg}$ bw daily for one month produced significant decrease of serum ALT and AST due to antioxidant effect and inhibition of oxidative stress.

The hapatoprotective effect of vitamin $\mathrm{E}$ is due to its free radical scavenger and also an effective inhibitor of autocatalytic process of lipid peroxidation; moreover it is the most important lipophilic antioxidant and exists mainly in the cellular membranes, thus helping to maintain membrane stability ${ }^{(27)}$.

In the present study, co-administration of subcutaneous TDN with orally MOLE and Vit. E daily for 4 weeks to male albino rats, caused statistically significant decrease in serum ALT, AST, ALP and total bilirubin activities and statistically significant increase in serum total protein in comparison to TDN.

Our results are supported by Azim et al. ${ }^{(12)}$ who found that oral administration of TDN to male mice in a dose of $150 \mathrm{mg} / \mathrm{kg}$ bw for 2 weeks followed by oral administration of Vit. E $100 \mathrm{mg} / \mathrm{kg}$ bw, idebenone $(200 \mathrm{mg} / \mathrm{kg} \mathrm{bw})$ and carnosine (200 $\mathrm{mg} / \mathrm{kg} \mathrm{bw}$ ) daily for one month produced more improvement in liver function than using each alone.

Also, our results are in agreement with Diab et al. ${ }^{(7)}$ who found that, co-administration of zinc oxide nanoparticles with Moringa extract and vitamin $E$ had a significant reduction in total bilirubin in rats than using Moringa or vitamin $\mathrm{E}$ alone, which may be due to synergistic effect between Moringa oleifera and vitamin $\mathrm{E}$ which in turn afforded the best protective effect.

The results of the present study as regard kidney function markers showed that, subcutaneous administration of TDNon alternate days for 4 weeks to male albino rats impaired kidney function represented by significant increase in serum urea and creatinine in comparison to control group.
Our results are supported by Morgan et al. (28) who found that, oral administration of 100 $\mathrm{mg} / \mathrm{kg}$ bw of TDN $(10 \mathrm{~nm})$ for 60 consecutive days to rats induced nephrotoxicity marked by significant increases in kidney indices (urea and creatinine).

The elevated renal indices indicated renal injury induced by TDN due to over deposition of TDN in kidney tissue and generation of ROS with subsequent depletion of antioxidant cell defenses that can result in disruption of prooxidant/antioxidant balance which increased the permeability of mitochondrial membrane and induction of mitochondrial membrane depolarization ${ }^{(29)}$.

Also, our results are in agreement with Abdou et al. ${ }^{(30)}$ who reported that, administration of TDN $(500 \mathrm{mg} / \mathrm{kg} \mathrm{bw})$ orally every other day for 60 days to rats produced significant elevation in serum urea and creatinine.

In the present study, co-administration of subcutaneous TDN with orally MOLE daily for 4 weeks to male albino rats caused statistically significant decrease in serum urea and creatinine in comparison to TDN which indicates improvement.

Also our results are supported by Abdou et al . ${ }^{(30)}$ who reported that, co-administration of TDN $(500 \mathrm{mg} / \mathrm{kg} \mathrm{bw})$ orally every other day for 60 days to rats with Moringa oleifera leaves extract (400 $\mathrm{mg} / \mathrm{kg} \mathrm{bw}$ ) daily for 60 days, produced significant reduction in serum urea and creatinine by suppressing oxidative stress and inflammation.

The mechanism of nephronprotection by Moringa oleifera is due to phytochemical constituents which contribute to its antioxidant activity and also could be attributed to its ability to antagonize the enhanced lipid peroxidation, which in turn stabilize the integrity of the cellular membranes. These properties may be mediated through direct trapping of the free radicals and also through metal chelation acid ${ }^{(31)}$.

In the present study, co-administration of subcutaneous TDN on alternate days with orally Vit. E daily for 4 weeks to male albino rats caused statistically significant decrease in serum urea and creatinine in comparison to TDN which indicate improvement.

Our results are in agreement with Abd et al . ${ }^{(32)}$ who found that, administration of vitamin $\mathrm{E}$ $(200 \mathrm{mg} / \mathrm{kg})$ orally to rats intoxicated with vancomycin produced significant reduction in levels of serum creatinine and urea as compared to vancomycin group and the nephroprotection of Vit. $\mathrm{E}$ is by acting as indirect vasodilator through cytosolic upregulation of phospholipid A2 and cyclooxygenase- 1 , which eventually leads to the 
release of prostacyclin which is a potent vasodilator, which lead to improvement the GFR and correct the serum levels of creatinine and urea.

Our results are in agreement with Morgan et al. ${ }^{(28)}$ who found that, co-administration of tiron (synthetic vitamin E analog) with TDN to male rats, significantly reduce the serum level of urea and creatinine; the markers for renal dysfunction, indicating improvement of kidney function and this may be due to the metal chelating properties of Vit . E, which reduce the deposition of TDN in kidney tissue.

Also our results are supported by AbdelDaim and Abdeen $^{(33)}$ who found that, oral administration of Vit. E to rats intoxicated with fipronil (insecticides) produced significant reduction in levels of serum creatinine and urea due to antioxidant effect.

In the present study, co-administration of subcutaneous TDN on alternate days with orally MOLE and Vit. E daily for 4 weeks to male albino rats caused statistically significant decrease in serum urea and creatinine in comparison to TDN and combined protection showed more improvement than using Moringa alone or vitamin E alone.

The results of the present study as regard histopathological changes in hepatic tissue in different studied groups showed that, subcutaneous administration of TDN on alternate days for 4 weeks to male albino rats produced histopathological changes in the liver and, these changes are in the form of marked mononuclear cellular infiltration. Also, dilated and congested blood vessel in portal tract area can be seen with thick wall while there was marked improvement of the hepatic tissue of the rats co-administrated Moringa oleifera leaves extract alone or Vit $\mathrm{E}$ alone or both with TDN.

Our finding are in agreement with Shakeel et al. ${ }^{(13)}$ who found that subcutaneous administration of TDN to rat on alternate days for 28 days in a dose of 50,100 , and $150 \mathrm{mg} / \mathrm{kg}$ bw produced histopathological changes in the liver and these changes was dose dependent being more in high dose.

Rizk et al. ${ }^{(25)}$ found that, administration of different doses of (TDN) $(50,250$ and $500 \mathrm{mg} / \mathrm{kg}$ body weight) injected intraperitoneally to mice for 7, 14 and 45 days, produced histopathological variations and abnormalities in the liver tissue and these changes were dose and duration dependent.

The appearance of inflammatory cells in liver tissue suggested that, TDN interact with enzymes and other proteins in the liver interstitial tissue, interfere with the antioxidant defence mechanism and lead to reactive oxygen species production that may result in an inflammatory response and dilated central blood vessel and blood sinusoids, due to, TDN alter the cell membranes permeability in the liver cells and the endothelial lining of blood vessels ${ }^{(\mathbf{1 3})}$.

Our finding are in agreement with El-bakry et al. ${ }^{(6)}$ who found that, oral administration of MOLE to rats intoxicated with carbon tetrachlorides leads to improvement in the histopathological changes in the liver induced by carbon tetra-chlorides due to its antioxidant effect.

Our results are supported by Azim et al. ${ }^{(12)}$ who found that oral administration of TDN to male mice in a dose of $150 \mathrm{mg} / \mathrm{kg}$ bw for 2 weeks followed by oral administration of Vit. E $100 \mathrm{mg} / \mathrm{kg}$ bw daily for one month produced significant improvement in hepatic histopathological changes due to antioxidant properties of Vit. E.

Our finding are supported by Abdel-Daim and Abdeen ${ }^{(33)}$ who found that, oral administration of Vit. $\mathrm{E}$ to rats intoxicated with fipronil (insecticides) improve the hepatic histopathological damages.

The results of the present study as regard histopathological changes in renal tissue in different studied groups showed that, subcutaneous administration of TDN on alternate days for 4 weeks to male albino rats produced histopathological changes in the kidney and these changes are in the form of area of hemorrhage, mononuclear cellular infiltration also; dilated and congested blood vessel with thick wall, while there was marked improvement of the renal tissue of the rats co-administrated Moringa oleifera leaves extract alone or Vit E alone or both with TDN.

Our finding are in agreement with AlRasheed et al. ${ }^{(34)}$ who found that, administration of TDN to rats produced histopathological variations and abnormalities in the renal tissue in the form of congested dilated glomerular capillaries, flattening of the epithelial lining of some tubules, exfoliation and pyknosis of some tubular cells with apparent luminal dilatation and intratubular cell debris .

Liu et al . ${ }^{(24)}$ stated that, TDN increased expression of nuclear factor kappa $\mathrm{B}(\mathrm{NF}-\mathrm{\kappa B})$ in TDN-treated rats due to oxidative stress, and elevated NF- $\kappa B$ could in turn, induce the synthesis of other inflammatory-related molecules that enhance kidney damage.

Our results are supported by Abdou et al. (30) who found that, co-administration of TDN to rats in a dose of $500 \mathrm{mg} / \mathrm{kg}$ bw orally every other day with Moringa olifera extract in a dose of (400 $\mathrm{mg} / \mathrm{kg} \mathrm{bw}$ ) orally every day for 60 days improve the histopathological changes induced by TDN and 
Hepato-Renal Toxicity of Titanium Dioxide Nanoparticles...

explained the anti-inflammatory effect of Moringa oleifera might be associated with diminished nuclear factor kappa B expression in TDN induced nephrotoxicity. Moringa oleifera exert its effect through its antioxidant and cytoprotective actions and distinctly suppressed kidney injury molecule-1 expression in the kidney. Moringa oleifera could also enhance the antioxidant defense through the induction of hemeoxygenase-1, and thereby acts as a potential therapeutic agent in preventing renal injury

Our results are in agreement with Morgan et al. ${ }^{(28)}$ who found that, co-administration of tiron (synthetic vitamin E analog) with TDN to male rats, markedly improve the histopathological changes induced by TDN because tiron significantly reversed the activation of fibrotic markers induced by TDN and improves the expression of Klotho gene which increases the resistance of kidney against oxidative stress.

Our finding are supported by Abdel-Daim and Abdeen ${ }^{(33)}$ who found that, oral administration of Vit. E to rats intoxicated with fipronil (insecticides) improve the renal histopathological damages.

\section{Conclusion:}

The results of the present study demonstrated that TDN induced hepatotoxicity represented by elevation of ALT, AST, ALP and total bilirubin and decreased total protein and nephrotoxicity represented by elevation of renal indices (urea and creatinine) and these results augmented by histopathological changes in both liver and kidney but in co-administration of either Moringa oleifera leaves extract or vitamin E or both with TDN produced more improvement in all these biochemical parameters and histopathological changes induced by TDN and the best improvement was in combination of both MOLE and vitamin $\mathrm{E}$ then MOLE alone then vitamin $\mathrm{E}$ alone .

\section{RECOMMENDATION}

- It is recommended to limit ingestion of TDN through non-essential drug additives, food colors, etc. and to decrease the risk of TDN toxicity.

- Where the controlling process to limit the uses of these nanoparticles is not easy to reach, there is a need to enrich our diet with antioxidants compounds such as Moringa oleifera leaves extract and vitamin $\mathrm{E}$

\section{REFERENCES}

1. Hasan S (2015): Review on Nanoparticles, Their Synthesis and Types. Research Journal of Recent Sciences, 4: 2-3.
2. Shukla R K, Sharma V, Pandey A K, Singh S, Sultana $S$ and Dhawan A (2011): Reactive oxygen species mediated genotoxicity induced by titanium dioxide nanoparticles in human epidermal cells. Toxicology in vitro, 25(1): 231-241.

3. Wang J X, Fan Y B, Gao Y, Hu Q H and Wang T C (2009): $\mathrm{TiO} 2$ nanoparticles translocation and potential toxicological effect in rats after intra-articular injection. Biomaterials, 30(27): 4590-4600.

4. Shakeel M, Jabeen F, Iqbal R, Chaudhry AS, Zafar S, Ali M and Asghar MS (2018): Assessment of titanium dioxide nanoparticles (TiO 2-NPs) Induced hepatotoxicity and ameliorative effects of Cinnamomum cassia in Sprague-Dawley rats. Biological trace element research, 182(1): 57-69.

5. Fahey J W (2005): Moringa Oleifera: Review Of The Medical Evidence For Its Nutritional, Therapeutic, And Prophylactic Properties. Part 1. Trees for life Journal, 1(5): 1-15.

6. El-bakry K, Toson ES, Serag M, and Aboser M (2016): Hepatoprotective effect of Moringaoleifera leaves extract against carbon tetrachloride-induced liver damage in rats. World journal of pharmaceutical research, 5(5): 76-89.

7. Diab AA, Zahra MH, AL-dohim SI and Hassan NJ (2015): The impact of MoringaOleifera extract and vitamin $\mathrm{E}$ against zinc oxide nanoparticles induced hepatotoxicity in male albino rats. J. Am. Sci., 11: 3341.

8. Duan Y, Duan J, Feng Y, Huang X, Fan W, Wang K and Geng Y (2018). Hepatoprotective activity of vitamin $\mathrm{E}$ and metallothionein in cadmium-induced liver injury in Ctenopharyngodonidellus. Oxidative medicine and cellular longevity, 2018 (9506543):1-12.

9. Kostomitsopoulos NG and Đurašević SF (2010): The Ethical Justification For The Use Of Animals In Biomedical Research. Archives of Biological Sciences, 62(3): 781-787.

10. AL -Rasheed NM, AL - Rasheed NM, Ab Del Baky NA, Faddah LM ,Fatani AJ, Hasan IH and Mohamad RA (2014): Prophylactic role of $\alpha$-lipoic acid and vitamin $\mathrm{E}$ against zinc oxide nanoparticles induced metabolic and immune disorders in rat's liver. European Review for Medical and Pharmacological Sciences, 18: 1813-1828.

11. Eshak MG, Hassanane MM, Farag IM, Shaffie NM and Abdalla AM(2015): Evaluation of Protective and Therapeutic Role of MoringaOleifera leaf extract on CCL 4-induced genotoxicity,hemotoxicity and hepatotoxicity in rats.Int.J. PharmTech Res., 7(2):392415.

12. Azim SAA, Darwish HA, Rizk MZ, Ali SA and Kadry MO (2015): Amelioration of Titanium Dioxide Nanoparticles-Induced Liver Injury In Mice: Possible Role Of Some Antioxidants. Experimental and Toxicologic Pathology, 67(4): 305-314.

13. Shakeel M, Jabeen F, Qureshi N A and Fakhr-eAlam M (2016): Toxic effects of titanium dioxide nanoparticles and titanium dioxide bulk salt in the liver and blood of male Sprague-Dawley rats assessed by 
different assays. Biological trace element research, 173(2): 405-426.

14. Shi H, Magaye R, Castranova V and Zhao J (2013): Titanium dioxide nanoparticles: a review of current toxicological data.Particle and Fibre Toxicology, 10(15):1-33.

15. Helmy AM, Sharaf-El-Din NA, Abd-El-Moneim RA and Rostom DM (2015): Histological study of the renal cortical proximal and distal tubules in adult male albino rats following prolonged administration of titanium dioxide nanoparticles and the possible protective role of 1-carnosine. The Egyptian Journal of Histology, 38(1): 126-142.

16. Rahman MM, Sheikh MM I, Sharmin SA, Islam MS, Rahman MA, Rahman MM and Alam MF (2009): Antibacterial Activity Of Leaf Juice And Extracts Of MoringaOleiferaLam. Against Some Human Pathogenic Bacteria. CMU J Nat Sci., 8(2): 219.

17. IFCC [International Federation of Clinical Chemistry] (1980): IFCC Methods for the measurement of catalytic concentration of enzymes, Part 2 IFCC Method for Aspartate aminotransferase (AST) and Part 3 IFCC Method for Alanine Aminotransferase (ALT). J. Clin. Chem. Clin. Biochem., 18: 521-534.

18. Scandinavien society (1974): The Committee on Enzymes of The Scandinavian Society for Clinical Chemistry and Clinical Physiology: Recommended Methods for the Determination of Four enzymes in blood. Scand. J. Clin. Lab. Invest., 32: 29.

19. Walter $M$ and Gerade $H$ (1970): Determination of the"Total"bilirubin and its conjugated "Direct" fraction. Microchem.J., 15:231.

20. Gomal AC, Bardawill CF and David MM (1949): Colorimetric methodto determine total protein.j.biol.chem., 177:751-755.

21. Fawcett JK and Scott J E (1960): A Rapid and Precise Method for The Determination Of Urea. J. Clin. Pathol., 13(2): 156-159.

22. Bartles $H$ and Bohmen M (1972): Colorimetric kinetic method to determine creatinine in serum or plasma. Clin. Chem. Acta., 37: 193-198.

23. Bancroft JD and Gamble $M$ (2002): Theory and practice of Histological Techniques. Fifth ed., Churchill Livingstone, London.

24. Liu H, Ma L, Zhao J, Liu J, Yan J, Ruan J and Hong F (2010):Biochemical toxicity of nano-anatase $\mathrm{TiO} 2$ particles in mice. Biol Trace Elem Res., 129 (1-3): 170180.

25. Rizk MZ, Ali SA, Hamed MA, El-Rigal NS, Aly HF and Salah HH (2017): Toxicity of titanium dioxide nanoparticles: Effect of dose and time on biochemical disturbance, oxidative stress and genotoxicity in mice. Biomedicine \& Pharmacotherapy, 90: 466-472.

26. Farag IM, Roshdya HM, Radwana HA, Ghalya IS, Salaha SH, Abdel-Rahimc EA and Abdallab AM (2018 ): Ameliorative role of ethanolic extract of Moringaoleifera leaf on aflatoxin B1-induced genotoxicity and biochemical alterations in rats Journal of The Arab Society for Medical Research, 13(1): 60.70.

27. Sodhi S, Sharma A, Brar APS and Brar RS (2008): Effect of $\alpha$ tocoferol and selenium on antioxidant status, lipid peroxidation and hepatopathy induced by malathion in chicks. Pesticide Biochem. Phys., 90(2): 82-86.

28. Morgan AM, Mi AEH and Noshy PA (2015): Reproductive toxicity investigation of titanium dioxide nanoparticles in male albino rats. World J. Pharm. Pharmaceut. Sci., 4(10): 34-49.

29. Zhao J, Li N, Wang S, Zhao X, Wang J, Yan J, Ruan J, Wang $H$ and Hong $\mathbf{F}$ (2010) :The mechanism of oxidative damage in the nephrotoxicity of mice caused by nano-anatase TiO2. J ExpNanosci., 5(5):447-462.

30. Abdou KH, Moselhy WA, Mohamed HM , ElNahass E and Khalifa AG(2018): Moringa oleifera Leaves Extract Protects Titanium Dioxide Nanoparticles-Induced Nephrotoxicity via Nrf2/HO-1 Signaling and Amelioration of Oxidative Stress. Biological Trace Element Research , 187(1): 181-191.

31. Verma AR, Vijayakumar M, Mathela CS and Rao CV (2009): In vitro and in vivo antioxidant properties of different fractions of Moringaoleifera leaves. Food and Chemical Toxicology, 47(9): 2196-2201.

32. Abd AH, Qasim BJ, Sahib $H B$ and Raheem $H$ (2016):Nephroprotective Effect of Vitamin $E$ and Origanumvulgare Extracts against Vancomycin Induced Nephrotoxicity in Rats. Int. J. Pharmaceut. Sci. Rev. Res., 36: 89-96.

33. Abdel-Daim MM and Abdeen A (2018). Protective Effects Of Rosuvastatin And Vitamin E Against Fipronil-Mediated Oxidative Damage And Apoptosis In Rat Liver And Kidney. Food and Chemical Toxicology, 114: 69-77.

34. Al-Rasheed NM, Mohamed AM, Baky NAA, AlRasheed N M and Mohammad RA (2013): Potential Impact Of Quercetin And Idebenone Against ImmunoInflammatory And Oxidative Renal Damage Induced In Rats By TDN Toxicity. Journal of oleo science, 62(11): 961-971. 